\title{
Poor or Just Feeling Poor-Situation in Albania
}

\author{
Ruzhdie Bici, Msc. PhD Candidate \\ Ahmet Mancellari, Prof. Dr. \\ Department of Economics, University of Tirana
}

doi: 10.19044/esj.2017.v13n10p105 URL:http://dx.doi.org/10.19044/esj.2017.v13n10p105

\begin{abstract}
There exist different methods and definition how to measure poverty. It can be measured by income or consumption, objectively or as a perception of individuals for their socio-economic situation.The objective and subjective poverty are highly correlated and both are influenced by socioeconomic factors. Till now, it is the objective poverty mostly considered while the subjective one has been analyzed only as a part of it. Assessments of the subjective poverty are more scarce, especially in the case of transition countries. Different studies proposed advantages and disadvantages of using each method. The significance of different factors shows the characteristics and the trend of monetary or subjective poverty. The national poverty is Albania is calculated through monetary poverty. There are a set of influenced factors related with household composition, geographic division, education and other socio-economic indicators. In this paper we analyze the perception of individuals for the poverty, the relationship of this perception with the objective poverty, and the socio-demographic factors that influence the probability of being poor. There are used the data from the Albanian Living Standard Measurement Survey (LSMS).
\end{abstract}

Keywords: Subjective poverty, objective poverty, multidimensional, determinants, logistic regression

\section{Introduction}

Poverty is multidimensional and depends not only on income or consumption but is also influenced by socio-economic factors (Van Praag and Ferrer-i-Carbonell, 2005). Poverty has been generally defined as more limited access, as no power or not having a necessary income level. Usually the corresponding analysis is also restricted to economic deprivation and misery. The way how to define the poverty level and poverty measurement is subject to extensive research (Ravallion and Lokshin, 2003; Ravallion, 1998). There has been a lot of discussion about the best approach to measure 
poverty, and the possible method that should be used. Poverty is usually defined as an absolute poverty or a relative poverty, monetary or not monetary one, and measured with income or consumption. Along with these objective indicators of poverty, an increasing attention is being devoted to the subjective indicators of poverty. In the focus of our paper is the subjective poverty: how an individual is considered as poor, through his/her perception. In this paper, we have tried to see poverty more as social factor and to focus on its relationship with economic factors.

Subjective measures can be used not only to assess the situation of a particular household but also to set or inform the choice of poverty lines, equivalence scales, economies of scale, and regional cost-of-living differences (Coudouel, 2002), and also well-being, quality of life, utility and not being socially deprived. It can also be useful to compare subjective and self-reported measures of well-being, with the objective measures. Kahneman and Krueger (2006) claim that subjective well-being has been useful in the consumer preferences and social welfare measurement. The subjective measure of poverty gives also information on subjective perception on welfare and interprets the poverty line as the cost of a given level of "utility" (Ravallion, 1998). Pradhan and Ravallion (1998) mentioned that by ignoring relative welfare considerations, conventional approaches based on (objective) absolute poverty lines (which attempt to fix the real value of the poverty line) will tend to underestimate poverty in urban areas versus rural areas. It will be interesting to observe differences in the perceived welfare of urban and rural population and explain this state of perception for the four regions of Albania. According to Ravallion (2011), the more common approach is to collect multiple indicators of the various dimensions of poverty, invariably including an index of command over market goods, but also including indicators for household characteristics and household composition, geographic differences, health and education attainment, access in basic services, standard of housing, etc.

Different empirical studies show the self-reported poverty dependent not only on household's socio-economic characteristics but also on the community deprivations (Guagnano et al., 2013). Matkovic (2006) observed that due to the relatively high standard of living in the past and high expectations of the population that living standards would increase in a relatively short period of time, the subjective perception of poverty in the entire region has been very much present during the first decade of economic transition.

It is supposed that as rich people are, they consider themselves as poor because they have not the possibility to buy another car, or to have another home. So as much they have, as much they want. On the other hand, the poor people say: "I need more and I am happy with what I have". Several 
studies show a weak correlation between the monetary approach to poverty and household's subjective perception of wellbeing (Herrera et al., 2006).The reason for the discrepancy is generally explored by incorporating into the subjective estimations factors as education, employment status, health status and permanent income (Kingdon and Knight, 2006). It is important to see the possibility of correlation and difference in the factors that influence subjective or objective poverty for Albania and for specific regions inside the country.

\section{Methodology}

The analysis is based on cross-sectional data Albania Living Standard Measurement Survey. From this survey, we collect information on different household or individual characteristics like: education, employment, dwelling and living condition, possessing a set of durables, migration, health, subjective poverty, fertility, etc.

The first LSMS in Albania was conducted in 2002 with a sample of around 3,600 households, and was repeated twice after a three years period, respectively in 2005 and 2008 by using the same methodology and sample design. The last LSMS was conducted in 2012 using comparable indicators and methodology but with a larger sample, 6,671 households to have representative data not only in four main regions but also in prefecture level.

The poverty level in Albania is measured through expenditure method, calculating absolute poverty line. The Living Standard Measurement Survey is a multidimensional survey that measures not only the objective poverty but also in a separate module collects information for self-perception on the level of poverty. In that module one member of the household (mainly head or most informed adult in the household) is asked for the level of poverty; financial situation of their household; possibility of improvements and how it will be in the future; if he/she is satisfied with the food consumption, health condition, and self-assessment for socio-economic status. Our data on subjective perceptions use the survey responses to a question: "Imagine yourself in 10 levels where in the first one stay the poorest people and in the highest levels stay the richest people. In which level will you put yourself? (SPL)". In the first level are the poorest households and the 10-th was the richest. This indicator is known as 'cantril indicator' (Cantril, H. 1965). Based on the given responses, the households that put themselves in the first two levels are considered as poor. To analyze the influence of socio-economic factors, the logistic regression based on SPSS software is used. The depended variable is the one related with the answer given to the question: “where you put yourself?" and is a dummy variable. 


\section{Self-perception of poverty compared with objective poverty}

Based on the respondent answer, as subjective poor households are classified those with answers belonging to the first two levels of SPL.

In 2002 the subjective poverty was $26.2 \%$, from $25.4 \%$ the objective one; in 2005 the subjective poverty was 25.9\%, from $18.5 \%$ the objective one; in 2008 the figures were 19.4\% and 12.4\%, respectively. The trend changed in 2012: the subjective poverty was only $12.2 \%$, lower than the objective poverty level of $14.3 \%$.

Figure 1: Objective poverty and subjective poverty by Regions

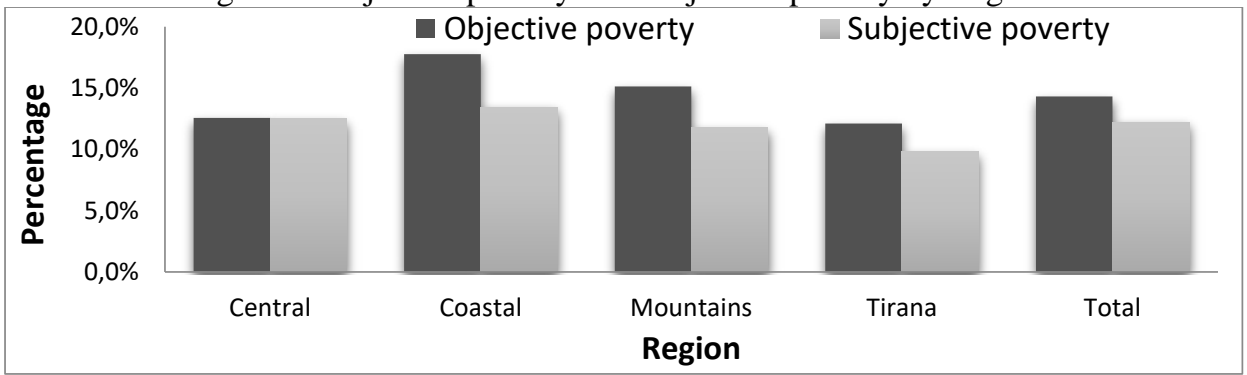

Source: LSMS 2012

Coastal have the highest objective and subjective poverty level. The trend in subjective poverty correlates with the objective one. The subjective poverty is significantly lower in Tirana (9.8\%) and even lower than the objective poverty for this region (12.1\%). The two measures are almost the same for the Central region.

The subjective poverty level during the period 2002-2012 is depicted in the Figure 2. It shows the trends of the subjective poverty based on their perception level by years. In 2002 the perception for their economic situation is higher in the first three levels; it is almost the same in 2005. The indicators for the first three levels (out of ten) are lower in 2008 and even lower in 2012. Figure 2 shows that this improvement tendency during the period 2002-2012 is enforced if we refer to the higher levels: in 2012 the line of subjective poverty from the fourth to the eighth level stays over the lines representing the other years, meaning that the individuals think that they are better off in 2012 compared with the previous years.

Figure 2: Subjective povertylevel

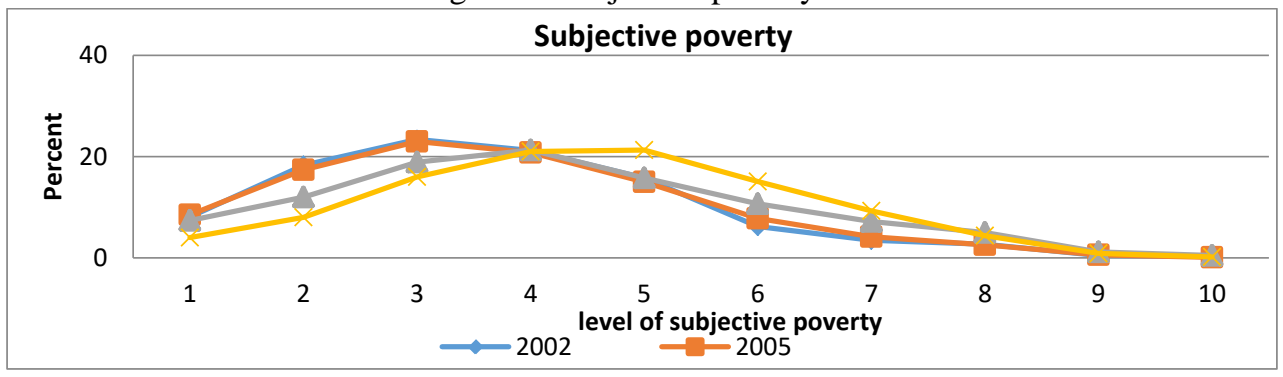

Source: LSMS 2002, 2005, 2008, and 2012. 
In 2012 the objective poverty is higher compared with 2008 but the feeling of the people is better, as they put themselves in a higher score. As shown in Figure 2, the line of subjective poverty in 2012 stays over the line of subjective poverty of 2008 and is higher after the 4th level. For the highest score the line in 2012 stay above other years. In 2012 the objective poverty is higher compared with 2008, but the subjective poverty shows the opposite (Table 1).

Table1: Comparing the subjective and objective poverty indicators

\begin{tabular}{|c|c|c|c|c|c|c|c|c|c|c|c|c|c|}
\hline & & \multicolumn{12}{|c|}{ subjective poverty } \\
\hline & & \multicolumn{3}{|c|}{2002} & \multicolumn{3}{|c|}{2005} & \multicolumn{3}{|c|}{2008} & \multicolumn{3}{|c|}{2012} \\
\hline & & non poor & poor & total & non poor & poor & total & non poor & poor & total & non poor & poor & total \\
\hline \multirow{4}{*}{$\begin{array}{c}\text { How } \\
\text { subjective } \\
\text { poor are } \\
\text { for each } \\
\text { objective } \\
\text { category } \\
\end{array}$} & Objectively non poor & 81.9 & 18.1 & 100 & 81.4 & 18.6 & 100 & 84.2 & 15.8 & 100 & 91.1 & 8.9 & 100 \\
\hline & Objectively poor & 50.1 & 49.9 & 100 & 42.4 & 57.6 & 100 & 55.3 & 44.7 & 100 & 69.6 & 30.3 & 100 \\
\hline & Total population subjective poor & 73.4 & 26.2 & 100 & 74.1 & 25.9 & 100 & 80.6 & 19.4 & 100 & 88.0 & 12.0 & 100 \\
\hline & & & & Total obj poor & & & Total obj poor & & & Total obj poor & & & Total obj poor \\
\hline \multirow{3}{*}{$\begin{array}{l}\text { How } \\
\text { Objective } \\
\text { poor are } \\
\text { for each } \\
\text { subjective } \\
\text { category }\end{array}$} & Objectively non poor & 82.8 & 51.6 & 74.6 & 89.4 & 58.7 & 81.5 & 91.5 & 71.5 & 87.6 & 88.7 & 63.7 & 85.7 \\
\hline & Objectively poor & 17.2 & 48.4 & 25.4 & 10.6 & 41.3 & 18.5 & 8.5 & 28.5 & 12.4 & 11.3 & 36.3 & 14.3 \\
\hline & total & 100 & 100 & 100 & 100 & 100 & 100 & 100 & 100 & 100 & 100 & 100 & 100 \\
\hline
\end{tabular}


However, when somebody says that he/she is "poor", it typically does not mean that he/she is unhappy. It cannot be surprising that income is not all that matters to "happiness" or "satisfaction with life". This means that we could not have the same percentage of people that are objectively poor, and also feel themselves as poor.

Table 1 shows the subjective poverty versus the objective one. From people that are the objectively poor about 30\% (exactly 28.5\%) of them percept themselves as poor in 2008, so they have overestimated the real situation where they are.

In 2002 about half of the objective poor people percept themselves as poor. Compared with the poor, objectively non-poor individuals are much better. In 2012, 1/10 of the individuals percept themselves as poor from 1/5 in 2002 and 2005. Referring to the subjective level of happiness for the life, positive perception of individuals is higher in 2008 compared with 2002 and 2005. This difference is higher in 2012 compared with 2002. The poor people (objectively measured), feel themselves better off from year to year. In 2012 figures shows a decrease of subjective poverty compared with the previous years: 12.0\% in 2012 from 19.4\% in 2008, 25.9\% in 2005 and $26.2 \%$ in 2002. The subjective poverty is lower in 2012 compared with the objective one. In the previous years, we see a decrease trend but it still shows that the subjective poverty is higher compared with the objective one.

The same as objective poverty, the subjective poverty is influenced by household composition like number of children or household size. Figure 3 reflects the comparability of objective poverty with the subjective one by the household size. As lower the household size is, lower is the percentage of people that thinks that they are poor and lower is also the percentage of people defined as poor by objective poverty.

Standard methods of setting poverty lines typically show that larger households are poorer in developing countries (Lipton and Ravallion, 1995). The relationship between poverty and household size is known, however, to be sensitive to measurement assumptions even within the class of standard “objective” methods (Lanjouw and Ravallion, 1995). 
Figure 3: The poverty level by household size

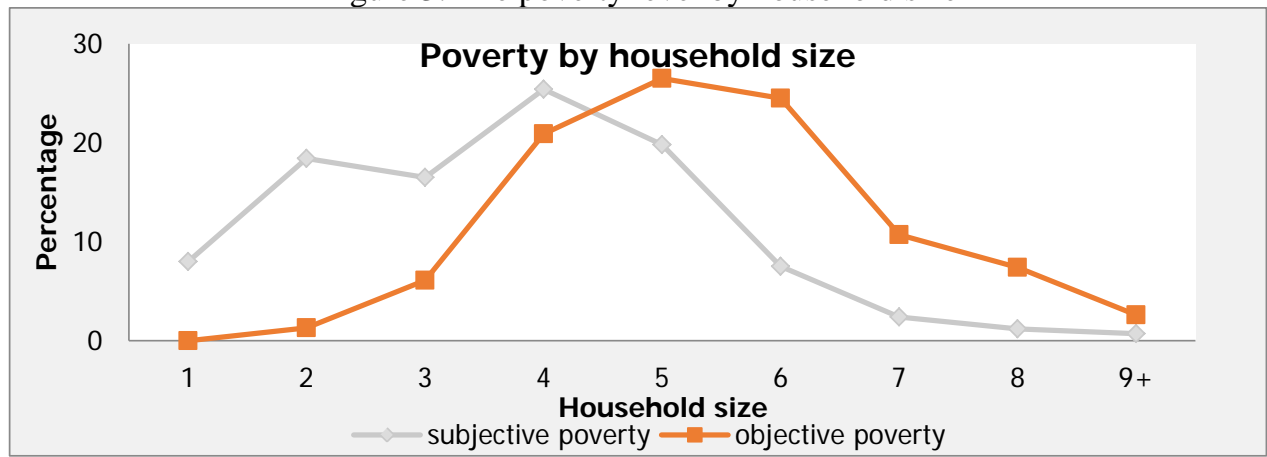

Source: Living Standard Measurement Survey-LSMS 2012

The per capita "objective" poverty line suggests that larger households tend to be poorer in developed and developing countries. The percentage of poor households is lower as lower is household size but tend to be larger for household with four to six members and again is decreased the percentage of poor households. In the households with four to six members, the shape of curve is in the maximum with more than $25 \%$ of the poor people. After this level, it shows a decreased percentage of the poor people. The poverty measures tend to fall as household size increases, although not monotonically but for both; objective poverty and subjective one are influenced by economies of scale (Figure 3). The objective poverty lines indicate that single-person families are not poor, while the subjective poverty lines indicate that we have a considerable number of single households that feel as poor. The curve is found to increase less than proportionately with household size, with somewhat stronger economies of scale indicated for objective than for subjective one. The comparison of poverty level (objective with subjective) by household size shows that lines in the figure have almost the same shape.

The same trend is discovered for both, self-perception of poverty and objective poverty. The objective poverty is higher than subjective poverty for households with five members and more.

Figure 4: Poor household by number of depended children aged 15 years old or less

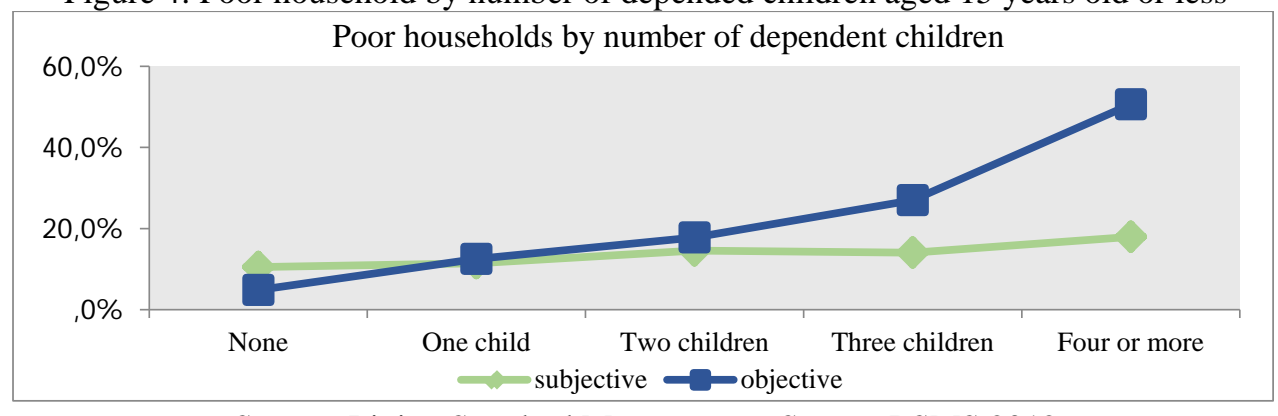

Source: Living Standard Measurement Survey-LSMS 2012 
The shape of the curves of poor people by household size is influenced by household composition. The percentage of the poor for households that have reported no dependent children 15 years old or less, is lower and almost zero for the objective poverty (Figure 4). This percentage is increased as the number of dependent children in the household is increased. The subjective poverty is increased slowly by increasing the number of children compared with the increase of objective one and this difference is significantly higher for households that have four or more children. This shows that subjective poverty is not so much influenced by the number of children. They may have not so good economic situation; their income or consumption is not so high but they may feel good.

An important role in the poverty situation and poverty reduction, have the geographic dimensions. Indirectly this variable shows the access that households have in health service, education, culture life, the connection and accesses in roads, towns, possibilities to find a job, etc. Based on LSMS 2012, referring to individuals that live in urban areas, about $1 / 3$ of them are fully or rather satisfied.

Table 2: Per capita food consumption and current level of food consumption as described from households

\begin{tabular}{|c|c|c|c|c|c|c|c|c|}
\hline \multirow{2}{*}{$\begin{array}{c}\text { Description of } \\
\text { current level of food } \\
\text { consumption }\end{array}$} & \multicolumn{2}{|c|}{2002} & \multicolumn{2}{|c|}{2005} & \multicolumn{2}{c|}{2008} & \multicolumn{2}{c|}{2012} \\
\cline { 2 - 10 } & Mean & Median & Mean & Median & Mean & Median & Mean & Median \\
\hline \hline More than adequate & 8,392 & 7,243 & 9,758 & 7,833 & 6,878 & 6,745 & 5,833 & 5,085 \\
\hline Just adequate & 5,428 & 4,791 & 6,848 & 6,022 & 5,543 & 5,050 & 5,320 & 4,607 \\
\hline Less than adequate & 4,308 & 3,792 & 5,361 & 4,718 & 4,736 & 4,231 & 4,600 & 4,027 \\
\hline \multicolumn{3}{c|}{ Source: LSMS 2002, 2005, 2008, 2012 } \\
\hline
\end{tabular}

The table 2 shows the food per capita consumption (mean and median) measured in monetary terms, and their perception/feeling for the level of food consumption. The highest share of consumption goes still for food products (INSTAT and World Bank, 2013). Comparing this level as measured and the self-reported quality level of food consumption for all years, it shows a high correlation of subjective self-reported and the objective measure.

The mean and median per capita consumption is higher for persons that have reported that the level of consumption is more than adequate, and is decreased with the people that say that the level of consumption is less than adequate. The objective poverty in 2012 is lower compared with 2002 and 2005 but higher compared with 20084. The food per capita consumption has a decreasing trend from year to year, particularly in 2012 compared with the

\footnotetext{
${ }^{4}$ www.instat.gov.al
} 
previous years. This happens because people tend to spend less even for food, so they not just live for eating but are poor also because of lack of other sources like durables, utility or less access in basic needs.

\section{Logistic regression results on determinants of subjective poverty}

As subjectively poor are considered individuals that put themselves in the first two lower stages (out of ten), all the others are considered as nonpoor. The dependent variable in our model is Yi; it is used in the regression as dummy variable where ' 1 ' are coded the subjective poor categories and as '0' are coded the non-subjective poor. Yi measure the satisfaction level of i individuals $(1 \leq \mathrm{i} \leq 25,325)$ respondent to the survey. The influence of different variables in the probability of being poor is identified in the regressive analyses.

The $\mathrm{Yi}$ is explained by $\mathrm{Xi}$, the set of variables that influence the perception of individuals for their consideration as regard the household level. To show the influence of independent variables, the binary logistic regression is used. As a reference category on the dependent variable, the category of non-poor people $(\mathrm{Y}=0)$ is used.

$$
\bar{Y}=\frac{\mathrm{e}^{\beta 0+\beta i X i}}{1+\mathrm{e}^{\beta 0+\beta i X i}}
$$

$\mathrm{Yi}=\beta 0+\beta \mathrm{ijXij}+\beta \mathrm{ihXih}+\beta \mathrm{igXig}+\mathrm{ui}$

ODDS $\{$ POOR=1 vs. 0$\}=\exp \{\beta 0+\beta i X i(j-g)\}$

$\operatorname{Pr}\{\operatorname{POOR}=1\}=\frac{\exp \{\beta 0+\beta \mathrm{iXi}(\mathrm{j}-\mathrm{g})\}}{1+\exp \{\beta 0+\beta \mathrm{iXi}(\mathrm{j}-\mathrm{g})\}}$

The second subscript of $\mathrm{Xij}$ (subscript $\mathrm{j}$ ) refers to the independent variable of demographic effects; other second subscripts (h and g) refer to regional and living conditions effects, respectively. So $\mathrm{Xj}$-g are independent variables related with demographic, health or living conditions. The classification of dependent variable, the coefficients and the significance level for each parameter are shown in the Table 3.

Demographic variables used are: number of children or the household size, gender of the head, and number of elderly people.

The number of children is used as categorical variable: 0-zero dependent children, 1-one children, 2-two children, 3- three or more dependent children. As a reference category is used 3- three or more dependent children. Having 0 or only 1 child means less chances that individuals feel themselves as poor; in general households having less children have less chances to be considered as poor. These households 
probably are satisfied not only with the current situation and put themselves in the highest levels but they also feel safer for their future situation and for the life of the children.

The "household size" is used as a continuous variable. Increasing the household size with one person, decreases the chances to feel as poor. So, the number of children or household size are factors that influence the probability of being subjectively poor.

The variable "gender of head" is used as dummy variable, coded as 0 -household head female, and 1-household head male; the last one used as a reference category. The results of the model show that persons who live in households that have female heads, feel themselves less poor compared with households with male head but this influence is not statistically significant.

Other variables that are included the regression as demographic dependent variables are number of elderly people, or elderly people by gender. At the beginning, we used two dummy variables referring to gender and age: female55 and males59. Females aged 55 and over ('female55no' coded as 1-at least one female 55 years old and over, and 0-no females aged 55 years old and over) and males aged 59 and over ('males59no'is coded as 1-at least one male 59 years and over, and 0 -no males aged 59 years and over). At the end we create one variable counting the number of elder people. We have an interesting result now: People from households that have two or more elderly members, feel themselves less poor compared with people living in households having no elderly or just one elderly member.

\section{Geographic variable}

Another important dimension of subjective poverty (and objective one), is the 'geographic' dimension. For analyzing the influence of geographic dimensions in the probability of feeling as poor, two variables are considered: region (four regions) and area (urban/rural). First, we consider 'rural' and 'urban' areas as a dummy independent variable, coded as 0-rural and 1-urban. According to the results of the model, the people who live in urban area percept themselves more poor (about 1.3 times more), compared with the people who live in rural areas. The results do not suggest that the conventional approach has underestimated urban versus rural poverty when compared to subjective poverty lines incorporating relative welfare effects, consistently with welfare perceptions. However, the regional poverty varies more depending on the method used. The urban versus rural poverty comparisons are of special interest in a developing country. Poverty comparisons between the two sectors have often been controversial, with different measurement methods giving very different results, including rank reversals (Ravallion and Bidani, 1994). It has been argued that, by ignoring relative welfare considerations, conventional approaches based on 
(objective) absolute poverty lines will tend to underestimate poverty in urban areas versus rural areas. Pradhan and Ravallion (2011), shows even larger differences between rural and urban poverty measures.

In addition, poverty varies across regions within a country, so creating a specific spatial poverty pattern (Sachs et al., 2001). Hence, analyzing the poverty according to geographic differences is important, due to the regional discrepancies in the level of socioeconomic development among urban and rural areas, and by regions. So, the second factors that influence the probability of being subjectively poor, is the region. The variable 'region' used in the model is a 'categorical' variable and refers to the four main regions of the country, where as reference category is used Tirana. The regions are coded as: 1-Central, 2-Coastal, 3-Mountain and 4Tirana. According to the results of the model, living in Tirana makes people feel themselves better off than people that live in Central, Coastal or Mountain region. This difference is more visible if we go in the smaller divisions (Betti et al., 2013).

\section{Health and education variables}

There are two variables used in the model, related with health: one related with the measured health, number of people in household that suffer from chronic disease (sufer2), and the other one related with health perception, number of people having bad health condition (health2). The three categories under the first variable (suffer2), are coded as follow:0-have no person that suffer; 1-one person that suffers from chronic diseases, 2-two persons that suffer from chronic diseases; and 3-three or more people that suffer from chronic diseases. As a reference category is used the category coded 3: three persons or more that suffer from chronic diseases.

Assessment of people for their health condition (health2) is also used as a categorical variable, coded as: 0 -have no one with bad health condition; 1-have one person in the household with bad health condition; 2- have two persons with bad health conditions; and 3-have three or more persons with bad health conditions. As a reference category is used category 3: having three or more people in the households that have bad health condition. Referring to the results of the model, the variable referring to people from households that have less than three persons with bad health conditions, does not influence significantly. Having a chronic illness is different from the perception of the health condition. Having more people that suffer from chronic diseases means more chances to self-assessment as poor.

The variable of education of the head is used as dummy variable where " 1 "-are households with lower education and " 0 " are the others that do not belong to this group. Having the head with lower education, implies more chances to feel as poor. Having not the necessary education level 
means that could not find a qualified and good job, not so much income at home, could not afford sending children at school, have not assets and could not afford meeting basic needs. This makes individuals falling in a "trap" of poverty and also feeling materially or socially deprived.

\section{Variables related with living condition and durables}

There are also some other independent variables that influence the living condition: variables that are related with possessing an asset, factors related with meeting the minimum basic needs in the households, and the objective poverty.

The independent variable for poverty is used as a dummy variable where 0-are non-poor and 1-poor; as a reference category is used poor. As describing poverty, we prove that subjective and objective poverty correlate together and also a set of influenced variables have the same trend. The people that are objectively poor feel themselves more poor than the people that are non-objectively poor (significant in 1\%).

Other variables also are used as dummy variables coded as 0 and 1 . As a reference category are used:“ 1 ”- have a car, “1”- have computer, “1”have refrigerator " 1 ”-have heating, “ 1 ”-own a home or having adequate housing condition. Not possessing at home a set of assets increases significantly the probability of feeling themselves as poor, like not having a car (2.9 times), a computer (2.7 times), a refrigerator (1.8 times).

The variable related with keeping home adequately warm, has not a significant influence in the subjective poverty. Ownership of the home have not a significant influence in the probability of feeling poor $(p=10 \%)$ but the variable related with having adequate dwelling decrease the chances that households feel as poor compared with the households that may have inadequate dwelling (significant at 5\% level). This means that the individuals may live for free, the owners are parents or they rent the home but they may have good condition at home, and all necessary assets.

Subjective poverty is influenced by individual perception for their life or financial situation. The positive feeling and assessment for their life and financial situation decrease the chances to feel poor.

\section{Conclusion}

Subjective poverty is closely related with the objective one. The same trend is shown for a set of variables for both, the objective and subjective poverty.

Measuring the trend of the highest share of total consumption, the food consumption is decreasing from year to year and there is a high correlation between objective figures measuring the food consumption, and the perception for food consumption. The objective poverty and the 
subjective one are both influenced by household composition like number of children, or household size. Geographic and demographic indicators are also important for objective, and subjective poverty. Being in the Tirana region, means more access in the public services and more chances for a better education and for finding a job, so people feel less poor. Other variables are related with dwelling condition and durables, influence the probability of being subjectively poor. Subjective poverty is influenced also from the health variables and the subjective perception for the life and financial situation. The assessment of subjective poverty is an important indicator for measuring the psychological condition of the households, welfare and wellbeing.

To design effective policies, deep researches are needed about the factors related not just with objective poverty but also with material and social deprivation.

\section{References:}

1. Betti G., Dabalen A., Ferré C. and Neri L. (2013), Updating Poverty Maps Between Censuses: A Case Study of Albania, in Laderchi C.R., Savastano S. (eds.), Poverty and Exclusion in the Western Balkans, Economic Studies in Inequality, Social Exclusion and Well-Being 8, Springer Science+Business Media, New York, pp. 55-70.

2. Callan, T. and Nolan, B. (1992), Low pay, poverty and social security, Working Papers, No. 36, Economic and Social Research Institute (ESRI), Dublin.

3. Cantril, H. (1965). The pattern of human concerns. New Brunswick, NJ: Rutgers University Press.

4. Coudouel, Aline; Hentschel, Jesko S.; and Quentin T. Wodon. (2002) "Poverty Measurement and Analysis", pp. 27-74 in The PRSP Sourcebook, Washington, D.C.: World Bank, http://siteresources.worldbank.org/INTPRS1/Resources/3836061205334112622/5467_chap1.pdf, retrieved 15 March 2014.

5. Deaton, A. (1997), The analysis of household surveys. A microeconometric approach to development policy. World Bank, Washington.

6. Guagnano, G., Santarelli E. and Santini, I. (2013), The determinants of subjective poverty in Europe: the role of household socioeconomic characteristics and social capital and the implications for public policies, Paper presented to the 4th annual IIPPE Conference, The Hague, July, 9-11.

7. Herrera, J. Razafindrakoto, M. and Roubaud, F. (2006), The determinants of subjective poverty: A comparative analysis in 
Madagascar and Peru, Development Institutions \& Analyses de Long terme, Paris.

8. INSTAT and World Bank, (2013), “Albania: Trends in Poverty 20022005-2008-2012”.

9. Kahneman, D. and Krueger, A. (2006), Developments in the measurement of subjective well-being, Journal of Economic Perspectives, 20(1): 3-24.

10. Kingdon, G. and Knight, J. (2006), Subjective well-being poverty vs. Income poverty and capabilities poverty, Journal of Development studies, 42(7): 1199- 1224.

11. Matkovic, G. (2006), Overview of poverty and social exclusion in the Western Balkan, Stanovnistvo, 44(1)1: 7-46.

12. Praag, B. and Ferrer-i-Carbonell, A. (2005), Happiness quantified. A satisfaction calculus approach, Oxford University Press: Oxford.

13. Pradhan, M. and Ravallion, M. (2011), Measuring poverty using qualitative perceptions of welfare, PolicyResearch Working Paper, World Bank.

14. Ravallion, M. (2011), Poor or just feeling poor? On using subjective data in measuring poverty, Policy Research Working Paper, no. 5968, February, World Bank.

15. Ravallion, M. and Lokshin, M. (2003 ), On the utility consistency of poverty lines, PolicyResearch Working Paper, no. 3157, October, World Bank.

16. Sachs, J., Mellinger, A. and Gallup, J. (2001), The Geography of Poverty and Wealth, Scientific American, 284(3): 70-75.

17. World Bank (2000), Making Transition Work for Everyone - Poverty and Inequality in Europe and Central Asia. A world free of poverty. Washington DC; World Bank (retrieved1March October 2014).

\section{Annex:}

Table 3: Logistic regression of subjective poverty

\begin{tabular}{|c|c|c|c|c|}
\hline \multicolumn{5}{|c|}{ Subjectively poor } \\
\hline Description & Name of variables & $\mathrm{B}$ & Odds ratio & Std. Error \\
\hline \hline Intercept & Intercept & 0.103 & & 0.679 \\
\hline Household size & hhsize & -0.252 & $0.777^{* * *}$ & 0.043 \\
\hline \multirow{2}{*}{ Absolute poverty } & {$[$ non-poor=0] } & -1.120 & $0.326^{* * *}$ & 0.140 \\
\cline { 2 - 5 } & {$[$ [Poor=1] } & $0(\mathrm{~b})$ &. &. \\
\hline \multirow{3}{*}{ Region } & {$[$ Central =1] } & 0.364 & $1.438+$ & 0.210 \\
\cline { 2 - 5 } & {$[$ Coastal =2] } & 0.138 & 1.148 & 0.213 \\
\cline { 2 - 5 } & {$[$ Mountain =3] } & 0.382 & $1.465+$ & 0.227 \\
\cline { 2 - 5 } & {$[$ Tirana =4] } & $0(\mathrm{~b})$ &. & \\
\hline
\end{tabular}




\begin{tabular}{|c|c|c|c|c|}
\hline \multirow{2}{*}{ Area } & [urban=1] & 0.296 & $1.345^{* *}$ & 0.104 \\
\hline & [rural=0] & $0(\mathrm{~b})$ & & \\
\hline \multirow{2}{*}{$\begin{array}{c}\text { Head with lower education } \\
\text { level }\end{array}$} & [head nolower $=0$ ] & -0.372 & $0.690 * * *$ & 0.101 \\
\hline & [head low edu $=1$ ] & 0 (b) & & \\
\hline \multirow{4}{*}{ Health condition } & [health2 $=0$ ] & 0.288 & 1.333 & 0.340 \\
\hline & [health2=1] & 0.273 & 1.314 & 0.342 \\
\hline & [health2=2] & 0.527 & 1.694 & 0.349 \\
\hline & [health2=3] & 0 (b) & & \\
\hline \multirow{4}{*}{$\begin{array}{l}\text { Any one suffer from chronic } \\
\text { disease }\end{array}$} & [suffer2=0] & -0.990 & $0.372 *$ & 0.448 \\
\hline & [suffer2=1,00] & -0.897 & $0.408^{*}$ & 0.452 \\
\hline & [suffer2 $=2,00]$ & -1.041 & $0.353 *$ & 0.458 \\
\hline & [suffer $2=3,00]$ & 0 (b) & & \\
\hline \multirow{2}{*}{ Ownership of the dwelling } & {$[\mathrm{own}=, 00]$} & 0.179 & 1.197 & 0.129 \\
\hline & [own $=1,00]$ & 0 (b) & & \\
\hline \multirow{2}{*}{ Do they have refrigerator? } & [refrigerator $=0$ ] & 0.581 & $1.788^{* *}$ & 0.201 \\
\hline & [refrigerator $=1]$ & 0 (b) & & \\
\hline \multirow{2}{*}{ Do they have computer? } & {$[$ computer $=0]$} & 0.985 & $2.678 * * *$ & 0.213 \\
\hline & [computer $=1]$ & $0(\mathrm{~b})$ & & \\
\hline \multirow{2}{*}{ Do they have a car? } & [no car $=0]$ & 1.077 & $2.937 * * *$ & 0.230 \\
\hline & [car=1] & 0 (b) & & \\
\hline \multirow{2}{*}{ Inadequate Heating at home } & {$[\mathrm{no}=0]$} & -0.130 & 0.878 & 0.105 \\
\hline & {$[\mathrm{Yes}=1]$} & 0 (b) & & \\
\hline \multirow{2}{*}{ Inadequate dwelling } & {$[\mathrm{no}=0]$} & -0.308 & $0.735^{*}$ & 0.141 \\
\hline & {$[$ Yes $=1]$} & $0(\mathrm{~b})$ & & \\
\hline \multirow{3}{*}{ Satisfy with the life } & [Fully=1] & -2.505 & $0.082 *$ & 1.076 \\
\hline & [Rather=2] & -1.165 & $0.312 * * *$ & 0.268 \\
\hline & {$[\mathrm{No}=3]$} & 0 (b) & & \\
\hline \multirow{3}{*}{$\begin{array}{l}\text { Satisfy with the financial } \\
\text { situation }\end{array}$} & [Fully=1] & 0.658 & 1.931 & 0.492 \\
\hline & [Rather=2] & -0.697 & $0.498^{* *}$ & 0.255 \\
\hline & {$[\mathrm{No}=3]$} & 0 (b) & & \\
\hline \multirow{3}{*}{ Feeling for financial situation } & [Improved=1] & -1.241 & $0.289 * * *$ & 0.252 \\
\hline & [The same=2] & -0.824 & $0.439 * * *$ & 0.120 \\
\hline & [Deteriorated =3] & $0(\mathrm{~b})$ & & \\
\hline \multirow{3}{*}{ Feeling for future } & [Improved=1] & -0.547 & $0.579 * *$ & 0.199 \\
\hline & [The same=2] & -0.724 & $0.485 * * *$ & 0.119 \\
\hline & [Deteriorated =3] & 0 (b) & & \\
\hline \multirow{2}{*}{ Gender of the head } & {$[$ female $=0]$} & -0.017 & 0.983 & 0.146 \\
\hline & [male=1] & 0 (b) & & . \\
\hline \multirow{3}{*}{ Elder people at home } & [elderTot=0] & 0.333 & $1.395^{*}$ & 0.151 \\
\hline & [elderTot=1] & 0.131 & 1.140 & 0.163 \\
\hline & [elderTot $=2$ ] & 0 (b) & & \\
\hline \multirow{4}{*}{$\begin{array}{l}\text { Number of dependent children } \\
\text { at home }\end{array}$} & children $=0$ & -0.543 & $0.581 *$ & 0.211 \\
\hline & children $=1$ & -0.218 & 0.804 & 0.195 \\
\hline & children $=2$ & 0.037 & 1.037 & 0.189 \\
\hline & children $=3$ & 0 (b) & & \\
\hline
\end{tabular}

$\wedge$ Logistic regression: $\mathrm{Y}=1 \rightarrow$ poor and $\mathrm{Y}=0 \rightarrow$ non poor, as a reference category is used $\mathrm{Y}=0$ $\wedge \wedge$ The significance level: ${ }^{* * *} \mathrm{p}<0.001,{ }^{* *} \mathrm{p}<0.01,{ }^{*} \mathrm{p}<0.05,+\mathrm{p}<0.1$ 